\title{
Examination of the Efficiency of Retrofitting Methods through Fragility Analysis
}

\author{
Murat S. KIRÇIL ${ }^{1}$ \\ Erdem Çaglar KOCABEY ${ }^{2}$
}

\begin{abstract}
Turkey had several devastating earthquakes throughout its history as it is located in a highly seismically active region. Thus, seismic evaluation and retrofitting of the existing structures to decrease the potential damage of the future earthquakes is an essential part of the earthquake relief plans. The aim of this study is to examine the efficiency of widely used two retrofitting methods of existing structures through fragility analysis. Fragility curves are useful tools to show the probability of structural damage due to earthquakes as a function of ground motion indices. Fragility curves of a hypothetical residential building which represents the existing building stock have been generated. Furthermore, fragility curves of two retrofitted building have also been obtained. The first one is a frame with jacketed columns and the second one has shear walls added to the existing frame. Fragility curves have been obtained based on both local and global damage criteria limits in terms of interstory drift ratio. The obtained damage probabilities have shown that the damage criteria either local or global which are used for generation of fragility curves are significantly effective on the results. Differences in damage probability indicate the importance of the damage criteria and corresponding limits used for the determination of damage probability.
\end{abstract}

Keywords: Fragility curve, damage probability, incremental dynamic analysis.

\section{INTRODUCTION}

Damage, observed after past earthquakes, has emphasized the need for risk assessment of the existing building stock to estimate the potential damage of future earthquakes. The $\mathrm{M}_{\mathrm{w}} 7.4$ 1999 Kocaeli and $M_{w} 7.22011$ Van earthquakes caused a considerable amount of economic losses, damage and a great number of causalities. This is due to not only the high seismicity but also due to the seismic vulnerability of the existing building stock. Most of the existing $\mathrm{RC}$ structures in Turkey are prone to earthquakes. Fragility curves allow estimation of the

\section{Note:}

- This paper has been received on March 20, 2018 and accepted for publication by the Editorial Board on December 24, 2018.

- Discussions on this paper will be accepted by September 30, 2019.

- https://dx.doi.org/10.18400/tekderg.408126

1 Department of Civil Engineering, Yildiz Technical University, İstanbul, Turkey - kircil@yildiz.edu.tr https://orcid.org/0000-0003-4447-9597

2 Department of Civil Engineering, Yildiz Technical University, İstanbul, Turkey erdemckocabey@gmail.com - https://orcid.org/0000-0002-0750-6114 
probability of structural damage due to earthquakes as a function of ground motion indices. Thus, fragility curves of different types of structures have always been a subject of investigations which are performed for vulnerability assessment to estimate the potential damage that may be caused by future earthquakes. Several studies have been carried out all over the world to investigate the potential damage to the existing building stock [1-16]. In this study, the effectiveness of two widely used retrofitting methods has been investigated through fragility curves. Incremental dynamic analyses were performed for considered buildings to determine the threshold of different damage levels in terms of interstory drift ratio and fragility curves have been obtained based on the determined threshold values. Furthermore, threshold of damage levels obtained with different approaches are compared.

\section{SAMPLE BUILDINGS}

The structural system of a 6-story hypothetical sample building that consists of R/C frames in both two directions has been investigated. Fig. 1 shows typical story plan of the sample building. The thickness of the concrete slab is $12 \mathrm{~cm}$ at each floor. Story height is $3.10 \mathrm{~m}$. Reinforcement type is S220 which has the characteristic yield strength of $220 \mathrm{MPa}$ and mean concrete compressive strength is assumed to be $10 \mathrm{MPa}$ considering the construction practice in Turkey before 2000. Those are realistic values for the buildings which are expected to exhibit poor performance during a severe earthquake.

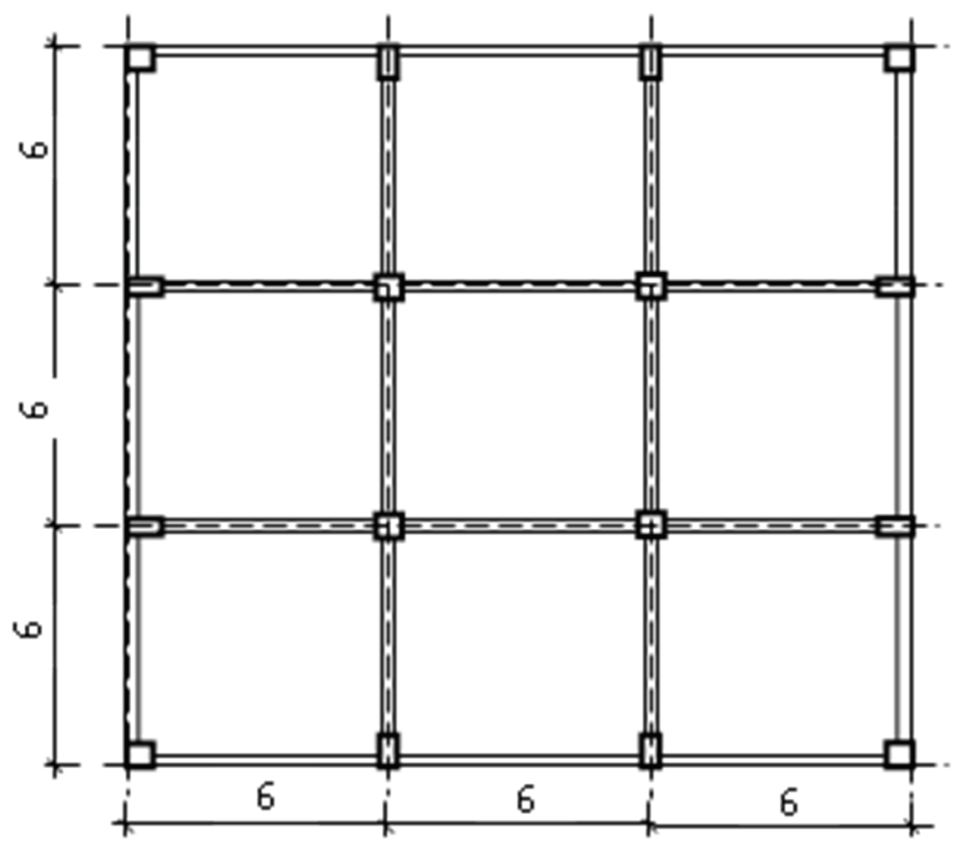

Figure 1 - Typical Story Plan of the Existing Building 
Mean reinforcement ratio of columns is approximately 0.008 which is lower than the accepted minimum reinforcement ratio. Beam dimensions are $25 \times 60 \mathrm{~cm}$ and mean beam reinforcement ratio is approximately 0.0035 . Typical deficiencies of such a building are material strength which is lower than the specified design strength and poor ductility of structural elements. The axial load on columns is higher than allowed especially in lower floors. Strong column and weak beam rule is not satisfied and also there is no confinement effect on structural members because of insufficient lateral reinforcement. The first mode period of the existing building, calculated with effective stiffness of structural elements, is $1.46 \mathrm{~s}$.

Although the main portion of the existing building stock does not have such a regular structural system, a regular plan building is used within the scope of this study to rationalize the structural behavior; so that, improvement in structural performance provided by each retrofitting method can be easily compared.

The assumed transverse reinforcement spacing is $25 \mathrm{~cm}$ since the existing buildings do not have adequate shear reinforcement to provide a significant confinement effect. Even $25 \mathrm{~cm}$ may be thought as low considering the shear reinforcement spacing of the significant portion of the existing building stock; however, it's high enough so that the confinement effect can be neglected. The calculated shear reinforcement spacing for retrofitting jackets is about 8$10 \mathrm{~cm}$ and shear reinforcement of jackets are taken into account for the calculation of the confinement effect. Figure 2 shows few example sections for beams and columns.
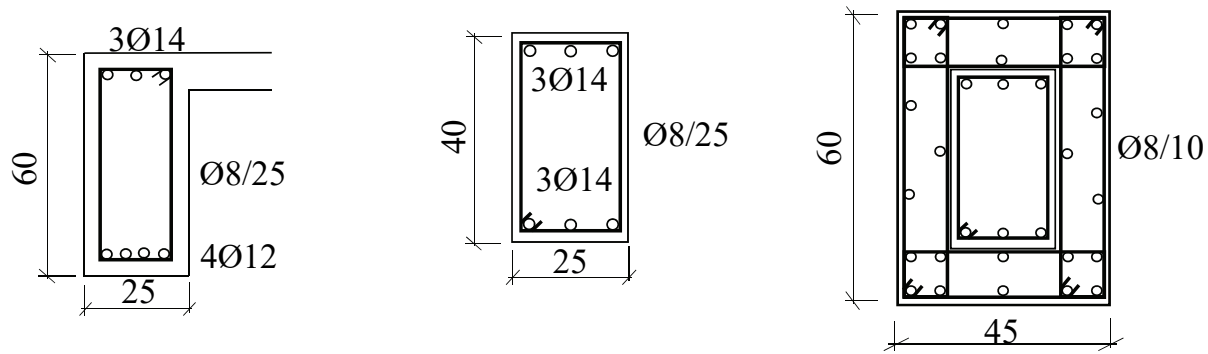

Figure 2 - Sample Sections for Existing Beam, Column and Retrofitted Column

As mentioned earlier, two different options which are widely used for retrofitting of the R/C structures were investigated within the scope of this study. The first one is jacketing columns of the existing structure and the latter is adding shear walls to the existing structural system. Jacketing improves strength of columns and also helps to improve strong column-weak beam behavior. The characteristic concrete strength of the jacket is $30 \mathrm{MPa}$ and characteristic yield strength of the reinforcing steel of the additional elements is $420 \mathrm{MPa}$. The floor plan of the structure, retrofitted by jacketing columns, is shown in Fig 3. The jacketing thickness is $10 \mathrm{~cm}$ and not constant because of the decreasing existing column dimensions through the building height. Thus, thickness of jacket increases up to $20 \mathrm{~cm}$ especially at upper floors so that a constant column section can be provided. The authors believe that constant dimensions of jacketed columns, along the height of retrofitted building, is an advantage to provide strong 
column-weak beam behavior and additional lateral stiffness to the retrofitted structure. The first mode vibration period of the retrofitted building, calculated with effective stiffness of structural elements, is $0.49 \mathrm{~s}$.

Another widely used method for strengthening is adding new shear walls to the structural system. This option provides strength and stiffness rather than ductility. New shear walls reduce the shear force and bending moment on the existing columns since they reduce the lateral displacement of the structure. However, ductility and ultimate strength of the existing columns is still low since their rotational capacity and strength can't be increased. Fig. 4 shows the floor plan of the structure with shear walls. The first mode vibration period of this building, calculated with effective stiffness of structural elements, is $0.40 \mathrm{~s}$.

The shear and bending reinforcement of all additional structural elements are determined based on the provisions given by TSDC[17] and TS500[18] using the internal actions obtained for the building located in Earthquake Zone 1 and Site Class B. The observed failure type of shear walls is bending. The shear failure for those shear walls are not expected considering that their mean shear capacity ratio is approximately equal to 0.87 in case of collapse and their height/length ratio 3.10.

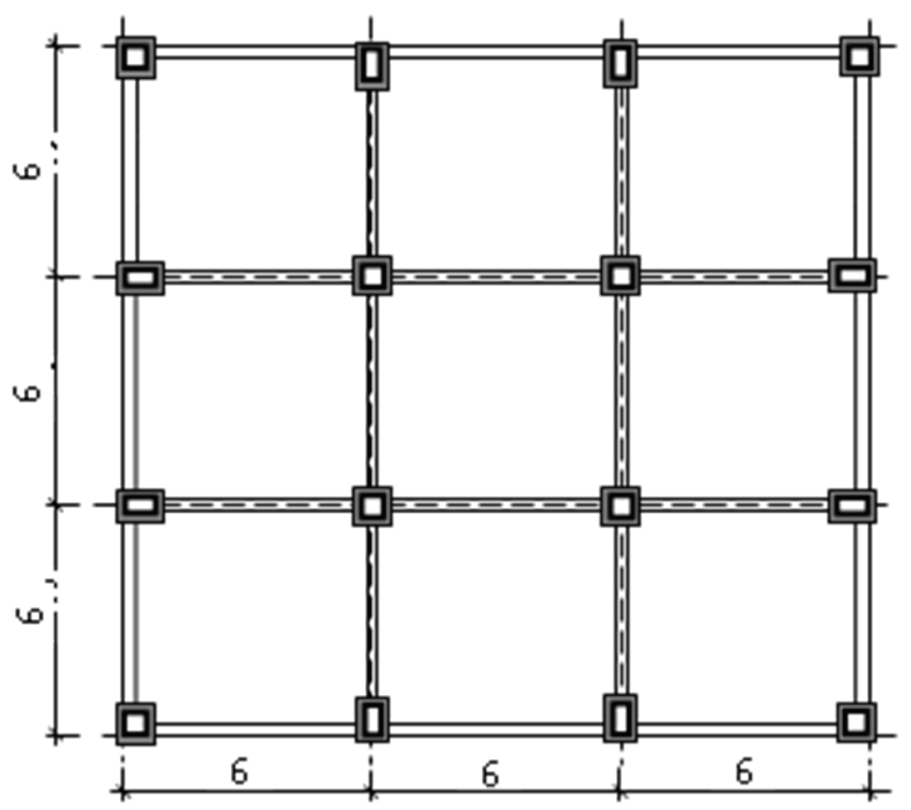

Figure 3 - Typical Floor Plan of the Sample Building (Retrofitted with Column Jacketing)

Although main portion of the existing building stock does not have such a regular structural system, a regular plan building is used within the scope of this study to refine the structural behavior; so that, improvement in structural performance provided by each retrofitting method can be easily compared. 


\section{GROUND MOTIONS}

The random nature of the earthquakes makes the damage estimation problem probabilistic. 13 ground motion record of 8 earthquakes with different magnitude, PGA and source distance have been used in this study to be able to take the random nature of the earthquakes into account. All the considered earthquakes are shown in Table 1. Note that, both X and Y component of Friuli, Colinga, Kocaeli (Eregli) and Kocaeli (Tekirdag) ground motions are used for analysis. All the selected ground motion records were recorded on Site Class B since the sample building is assumed to be constructed on this type of soil. Table 1 shows the considered earthquakes.

Table 1 - Ground Motions

\begin{tabular}{cccccc}
\hline Event & Year & Mag. & $\mathrm{R}_{\text {RUP }}(\mathrm{km})$ & PGA(g) & Site Class \\
\hline Kocaeli, Turkey (Eregli) & 1999 & 7.51 & 58.3 & 0.06 & $\mathrm{~B}$ \\
Kocaeli, Turkey (Tekirdag) & 1999 & 7.51 & 16.4 & 0.12 & $\mathrm{~B}$ \\
Coalinga (Perkfield-Cholame) & 1983 & 6.36 & 42 & 0.62 & $\mathrm{~B}$ \\
San Fernando (Upland - San Antonio Dam) & 1971 & 6.61 & 46.8 & 0.62 & $\mathrm{~B}$ \\
Friuli (Barcis) & 1976 & 6.5 & 49.1 & 0.25 & $\mathrm{~B}$ \\
Imperial Valley & 1977 & 6.53 & 50.1 & 0.11 & $\mathrm{~B}$ \\
(Pachute test site) & 1989 & 7.58 & 8.5 & 0.51 & $\mathrm{~B}$ \\
Loma Prieta (Saratoga) & 1992 & 7.28 & 69.2 & 0.1 & $\mathrm{~B}$ \\
Landers (Amboy) & 1994 & 6.69 & 20.11 & 0.46 & $\mathrm{~B}$ \\
Northridge (Castaic) & & & &
\end{tabular}

\section{DAMAGE LEVELS}

For the present study, 3 different approximations have been adopted to determine the threshold of damage levels in terms of inter-story drift ratio. The first one is analytic which is based on the determination of the mean inter-story drift limits obtained from incremental dynamic analyses at different damage states. The considered damage states are Slight, Minimum, Extensive and Collapse, respectively. The inter-story drift ratio limit for slight damage is assumed to be the inter-story drift ratio at first reinforcement yield in either column or beam section. Inter-story drift ratio limits for minimum and extensive damage level have been determined based on the strain limits given by the Turkish Seismic Design Code [17] as shown in Table 2.

The minimum damage limit is assumed as the inter-story drift ratio related to the first minimum section damage of a structural system element. The max. inter-story drift ratio of extensive damage limit is assumed to be reached at first beam section collapse based on the strain limits given in Table 2. The partial collapse limit corresponds to max. inter-story drift ratio at first column section collapse and finally collapse limit is defined as the max. interstory drift ratio causing frame mechanism. 
Table 2 - Strain Limits of Section Damage Levels

\begin{tabular}{ccc}
\hline $\begin{array}{c}\text { Section damage } \\
\text { level }\end{array}$ & Strain limit for concrete & Strain limit for reinforcement \\
\hline Minimum & 0.004 & 0.01 \\
Extensive & $0.004+0.0095\left(\rho_{\mathrm{s}} / \rho_{\mathrm{sm}}\right) \leq 0.0135$ (confined) & 0.04 \\
Collapse & $0.004+0.013\left(\rho_{\mathrm{s}} / \rho_{\mathrm{sm}}\right) \leq 0.0180$ (confined) & 0.06 \\
\hline
\end{tabular}

Note that the approximation given above, which is used for linking the inter-story drift ratio and strain limits given by Turkish Seismic Design Code[17], is subjective. On the other hand, Turkish Seismic Design Code[17] defines structural performance levels based on the rate of the damaged structural elements at each story. However, this approximation is not practical for such a study. Table 3 shows the drift ratio limits obtained following the procedure explained above. Those mean inter-story drift ratio limits will be called local damage criteria in the remaining part of the text since they have been determined using the local damage limits.

Table 3 - Inter-story Drift Limits Corresponding to Local Section Damages

\begin{tabular}{cccc}
\hline \multirow{2}{*}{ Damage level } & \multicolumn{3}{c}{ Mean interstory drift ratio (\%) } \\
\cline { 2 - 4 } & Existing & Jacketing & Shear wall \\
\hline Slight & 0.2 & 0.3 & 0.2 \\
Minimum & 1.5 & 1.8 & 0.9 \\
Extensive & - & 3.7 & - \\
Part. collapse & 2.7 & 6.6 & 3.3 \\
Collapse & 5.4 & 7.1 & 5.5 \\
\hline
\end{tabular}

The extensive damage limit is defined as first section collapse of a beam section as mentioned above. As seen from Table 3, the extensive damage limit could not be determined for the existing and the retrofitted building with shear walls, since strain limit of the collapse section damage for columns is reached before strain limit of collapse section damage for beams with a little increase in spectral acceleration. It is believed that the main reason is strong beamweak column mechanism commonly encountered in such buildings.

The second approximation is based on the global damage levels and corresponding interstory drift limits proposed by Rosetto and Elnashai [19]. Table 4 shows the aforementioned limits. Finally, the last approximation is the determination of yield and collapse states analytically through the incremental dynamic analysis following the definitions given by Vamvatsikos and Cornell [20]. Results are sown in Table 5. Inter-story drift ratio limits, given in Table 4 and 5, are based on the global structural behavior while those given in Table 3 are based on the local section damage limits. 
Table 4 - Inter-story Drift Limits (Global)

\begin{tabular}{cc}
\hline Damage level & Interstory drift ratio (\%) \\
\hline Light & 0.19 \\
Moderate & 0.56 \\
Extensive & 1.63 \\
Part. collapse & 3.34 \\
Collapse & $>4.78$ \\
\hline
\end{tabular}

Table 5 - Interstory Drift Limits Obtained With Incremental Dynamic Analysis

\begin{tabular}{cccc}
\hline \multirow{2}{*}{ Damage level } & \multicolumn{3}{c}{ Mean inter-story drift ratio (\%) } \\
\cline { 2 - 4 } & Existing & Jacketing & Shear wall \\
\hline Yield & 0.8 & 0.69 & 0.28 \\
Collapse & 3.06 & 4.39 & 2.17 \\
\hline
\end{tabular}

\section{INCREMENTAL DYNAMIC ANALYSIS}

Incremental dynamic analysis (IDA) has been used to determine the damage thresholds corresponding to aforementioned damage levels. This method was discussed comprehensively by Vamvatsikos and Cornell [20]. IDA is a useful method to produce curves which show the relationship between the selected ground motion intensity measure versus the selected damage indicator. For this study 5\% damped elastic spectral acceleration and maximum inter-story drift ratio is selected as intensity and damage measure, respectively. Each ground motion is scaled up monotonically with respect to the individual spectral acceleration based on the corresponding fundamental period of the considered building. Thus, the maximum inter-story drift ratio, obtained for each step of IDA, is the result of a non-linear time history analysis which is carried out for a certain elastic spectral acceleration. Up to the yield point, the relationship between spectral acceleration and the maximum interstory drift ratio is linear. However, the curve leaves the linear path as soon as a yielding which causes a significant decrease in the slope of the curve -in other word stiffness of the structure- is observed. When the slope of the curve decreases $20 \%$ of the initial slope of the IDA curve then the analyzed structure is assumed to have collapsed [20]. If dynamic instability as a result of non-converging run is observed before IDA curve's slope decreases to the limit value mentioned above then spectral acceleration level of the non-converging run is assumed as the collapse capacity. Seismostruct [23] has been used as a structural analyses software tool for IDA. Seismostruct uses the Newmark scheme with automatic time-step adjustment for optimum accuracy for the direct integration of the equations of motion during time history analysis of a 3-dimensional model. The considered hysteretic behavior of reinforcement and concrete are Bilinear and Mander model [17, 21], respectively. The fiber section model has been used which considers strain of each point of the section based on the aforementioned material models. Rigid diaphragm behavior of the slabs is considered during the analyses.

Fig. 5 shows typical IDA curves of the considered buildings obtained for Imperial Valley ground motion. Yield and collapse points are indicated on the figure. 


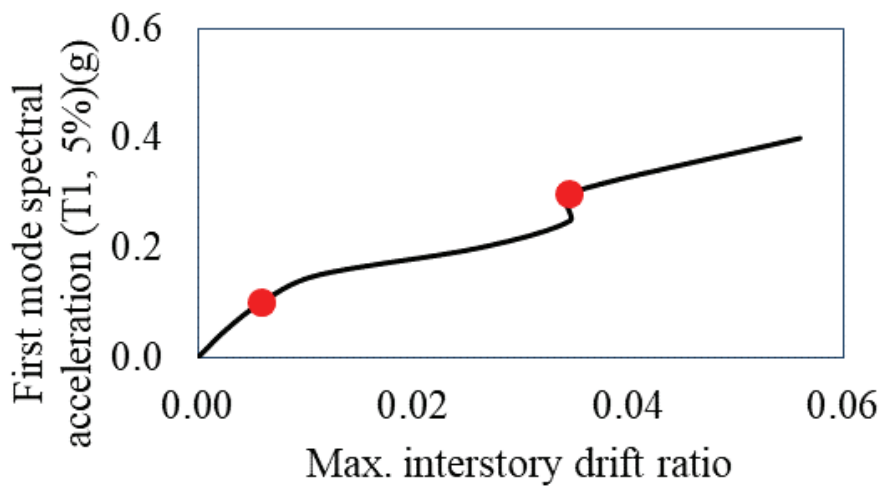

(a) IDA Curve of the Existing Building

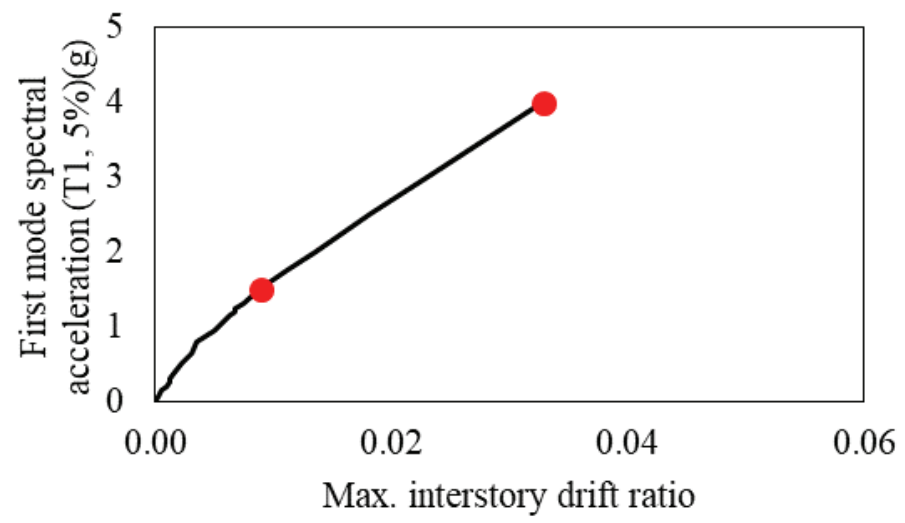

(b) IDA Curve of the Retrofitted Building by Jacketing Columns

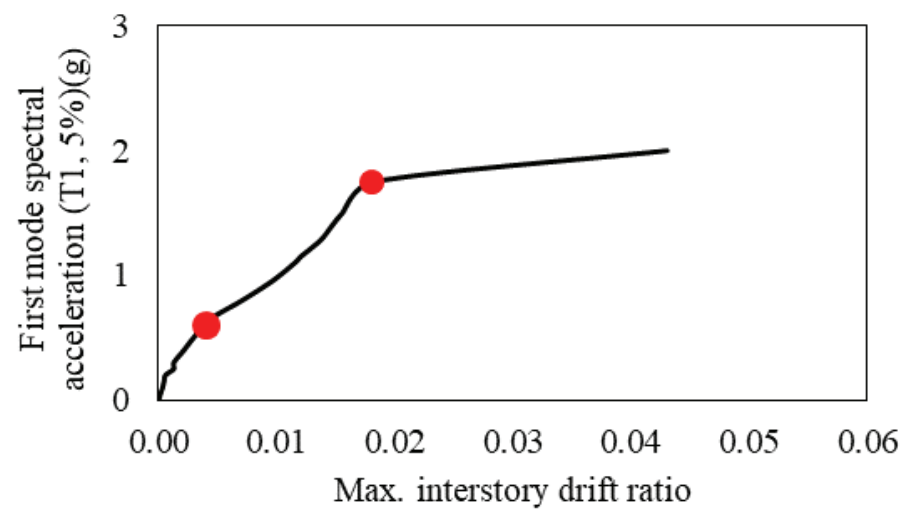

(c) IDA Curve of the Retrofitted Building by Adding Shear Walls

Figure 5 - IDA Curves Obtained for Imperial Walley Ground Motion 
All IDA curves obtained for all the considered building are given in Fig. 6, Fig.7 and Fig. 8 with their yield and collapse point.

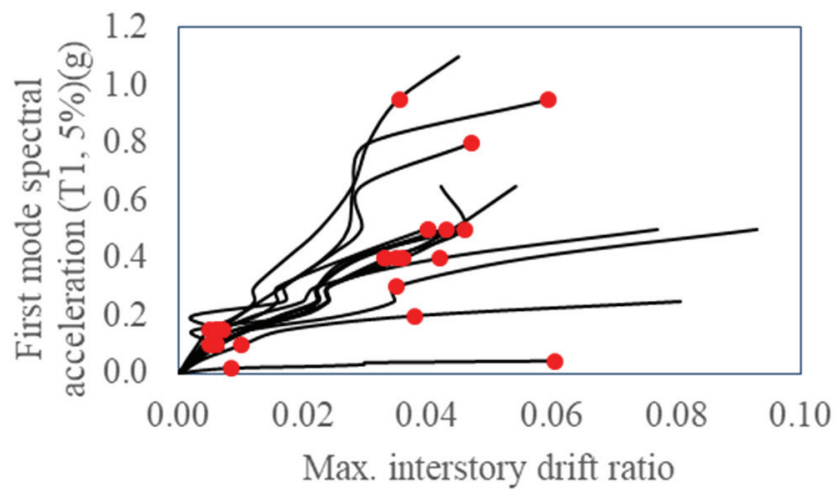

Figure 6 - All IDA Curves Obtained For the Existing Structure

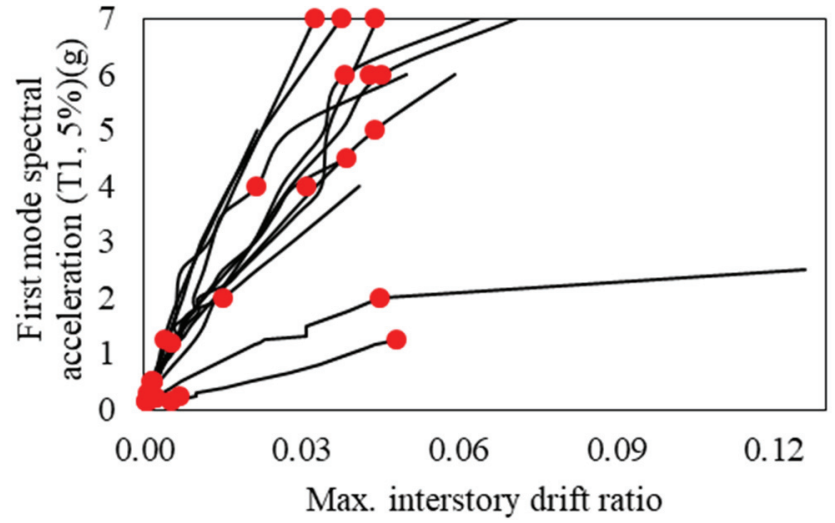

Figure 7 All IDA Curves Obtained For the Retrofitted Building by Jacketing the Columns

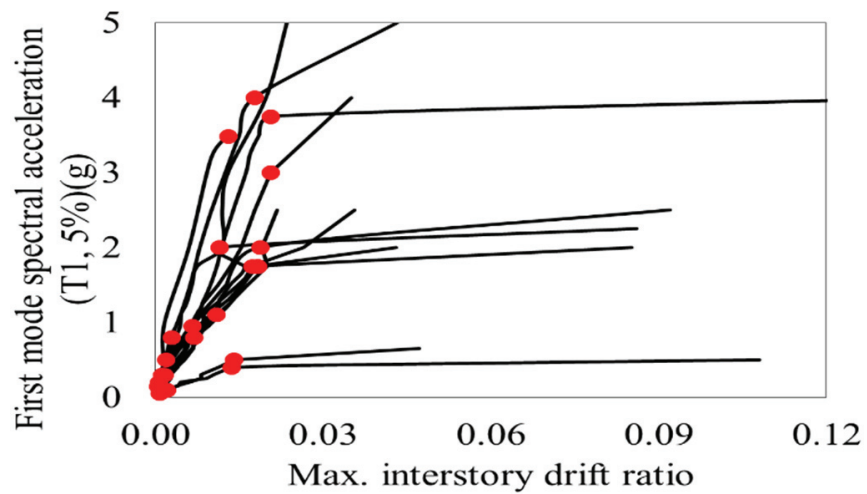

Figure 8 All IDA Curves Obtained For the Retrofitted Building by Adding Shear Walls 


\section{FRAGILITY CURVES}

Fragility curves express the probability of structural damage due to earthquakes as a function of ground motion indices. In the present study, fragility curves are constructed in terms of elastic spectral acceleration as mentioned before. Fragility curves can be expressed in the form of two-parameter lognormal distribution functions. Based on this assumption, the probability of reaching or exceeding a limit state (LS) at a given earthquake intensity can be expressed as follows

$$
P(L S)=P\left(d_{L S} \leq d_{\max }\right)=1-\Phi(r)
$$

where $d_{L S}$ and $d_{\max }$ are limit state capacity and maximum demand, respectively. By assuming a lognormal distribution, the standard normal variant can be expressed as follows

$r=\frac{\ln d_{L S}-\lambda_{D}}{\sqrt{\xi_{L S}^{2}+\xi_{D}^{2}}}$

where $\lambda_{D}$ is mean value with lognormal distribution and it can be expressed in terms of the mean of the maximum response $\left(d_{\max }\right)$ and its dispersion $\left(\xi_{D}\right)$.

$\lambda_{D}=\ln \bar{d}_{\max }-\frac{\xi_{D}^{2}}{2}$

$\xi_{\mathrm{LS}}$ is the lognormal standard deviation of a limit state. It is assumed to be 0.3 for the limits given in Table 4 by following the Jeong and Elnashai [22]. Lognormal standard deviation of other limit states, given in Table 3 and 5 were calculated using the results obtained from IDA.

The dispersion of maximum demand $\xi_{D}$ is obtained as the combination of uncertainties associated with demand estimation as follows

$\zeta_{D}=\sqrt{\ln \left(1+\left(\frac{\sigma_{r}}{\bar{d}_{\max }}\right)^{2}\right)+\ln \left(1+\left(\frac{\sigma_{c}}{\bar{d}_{\max }}\right)^{2}\right)+\ln \left(1+\left(\frac{\sigma_{D}}{\bar{d}_{\max }}\right)^{2}\right)}$

where $\sigma_{r}$ and $\sigma_{c}$ are the standard deviations due to randomness in earthquake records and material properties, respectively. $\sigma_{r}$ is considered by using 13 ground motion records. The dispersion in material properties has been considered using the standard deviation of $5 \mathrm{MPa}$ following the Bartlett and MacGregor [23]. $\sigma_{D}$ is standard deviation of structural response. Fig.9-11 show the fragility curves obtained for all considered buildings.

The target performance of earthquake resistant design of a residential buildings is to satisfy the Immediate Occupancy (IO), Life Safety (LS) and Collapse Prevention (CP) performance levels under the effect of earthquakes with probability of exceedance of $50 \%, 10 \%$ and $2 \%$, respectively. Table 6,7 and 8 show the probability of exceedance of the considered performance levels under the effect of earthquakes given by TSDC[17] for Earthquake Zone 1 and Site Class B with aforementioned probability of exceedance. The slight, extensive and partial collapse damage levels, given in Table 3, are related to IO, LS and CP performance levels, respectively. 


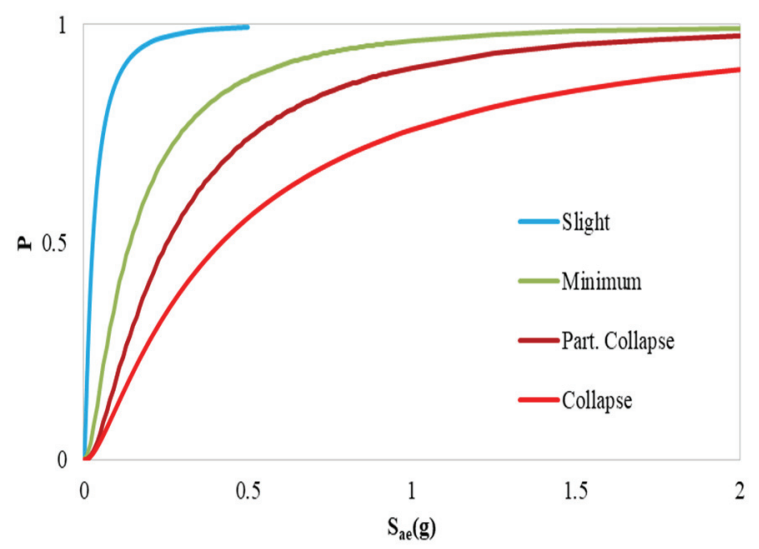

(a) Fragility Curves of the Existing Building (Local Damage Criteria)

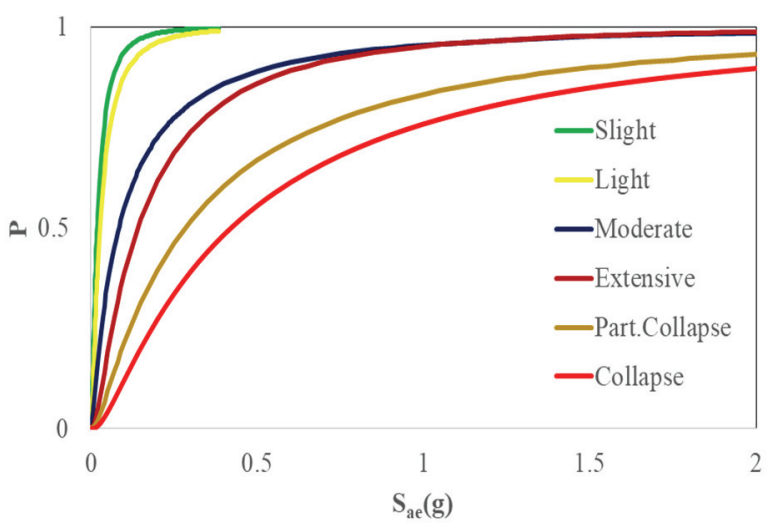

(b) Fragility Curves of the Existing Building (Global Damage Criteria)

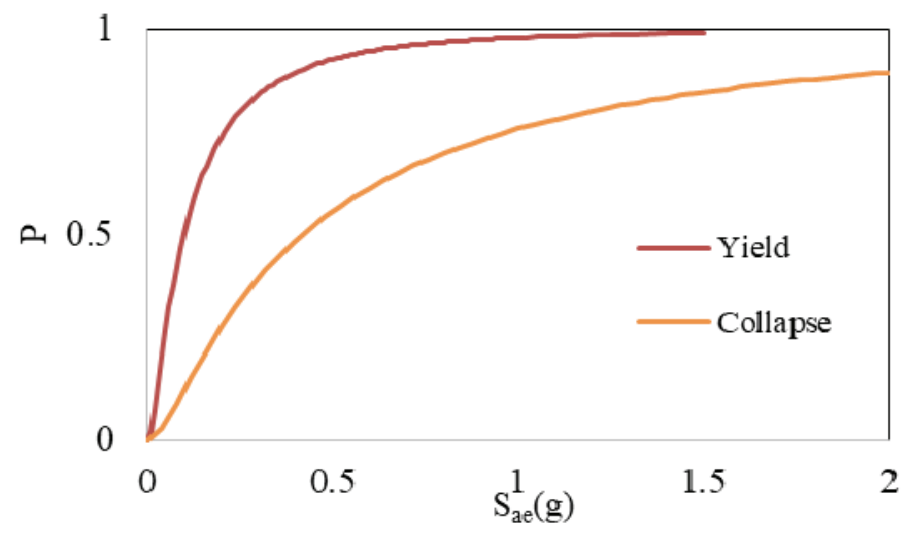

(c) Fragility Curves of the Existing Building (Global Damage Criteria / IDA)

Figure 9 - All IDA Curves Obtained for the Existing Building 


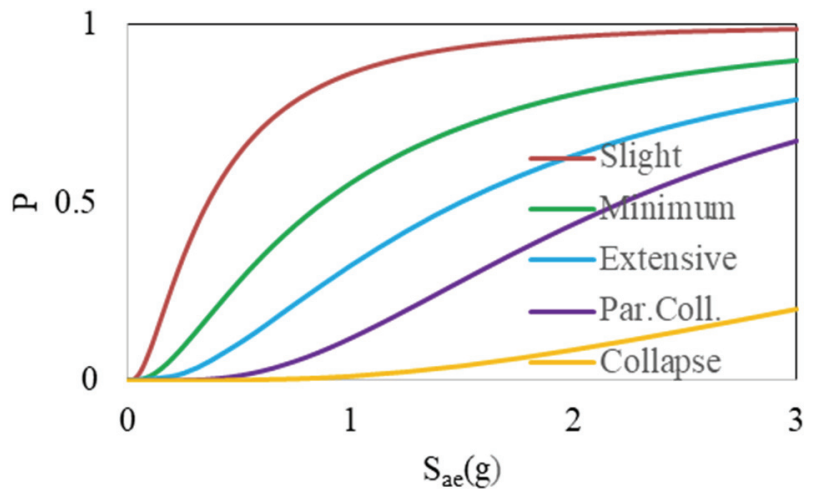

(a) Fragility Curves of the Retrofitted Building with Jacketed Columns (Local Damage Criteria)

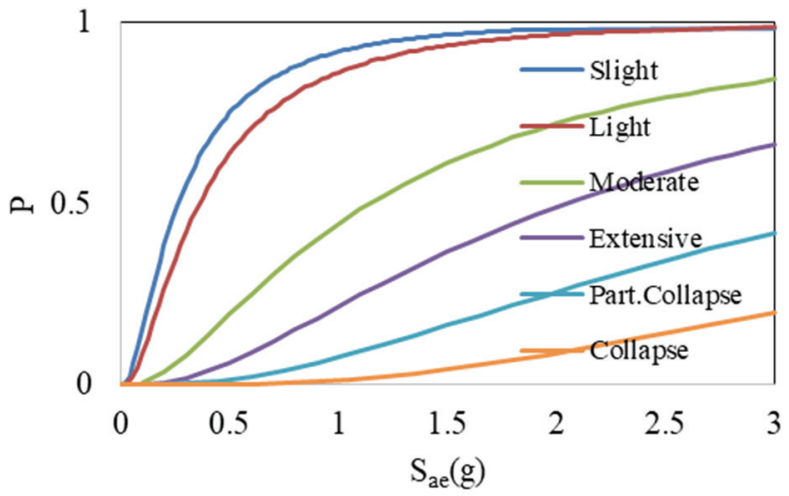

(b) Fragility Curves of the Retrofitted Building with Jacketed Columns (Global Damage Criteria)

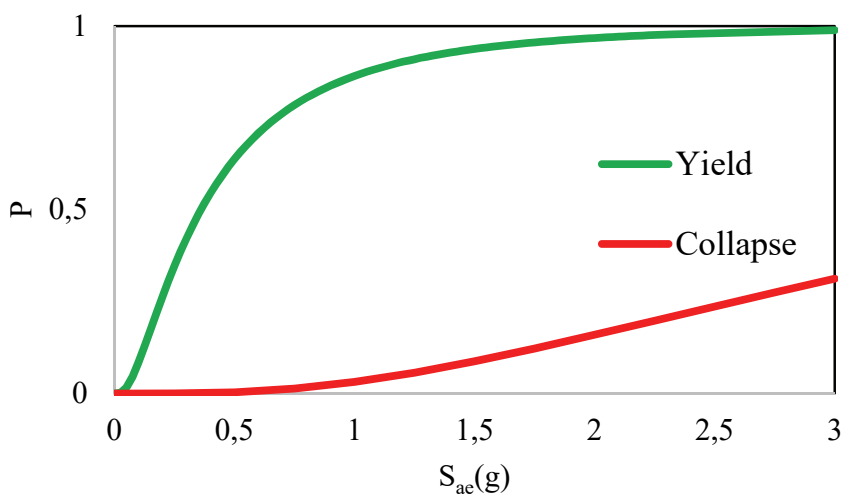

(c) Fragility Curves of Retrofitted Building with Jacketed Columns (Global Damage Criteria / IDA)

Figure 10 - Fragility Curves of the Retrofitted Building with Jacketed Columns 


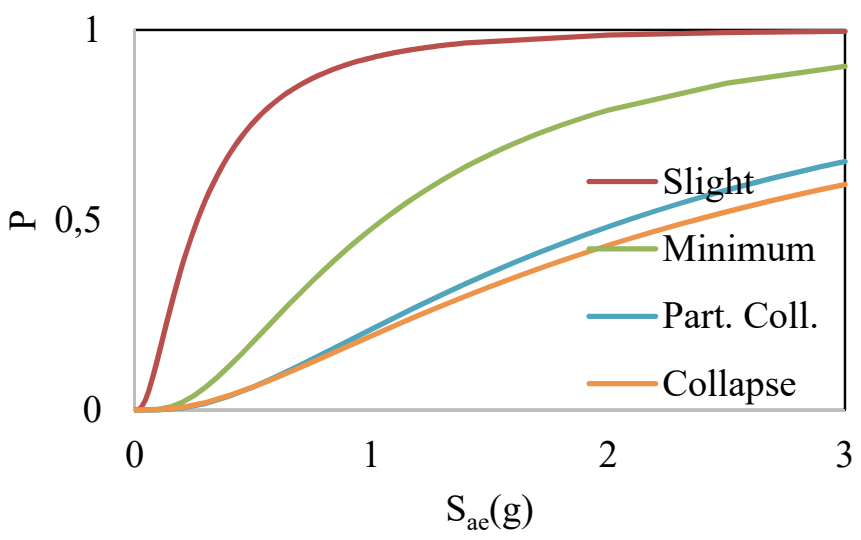

(a) Fragility Curves of the Retrofitted Building with Shear Walls (Local Damage Criteria)

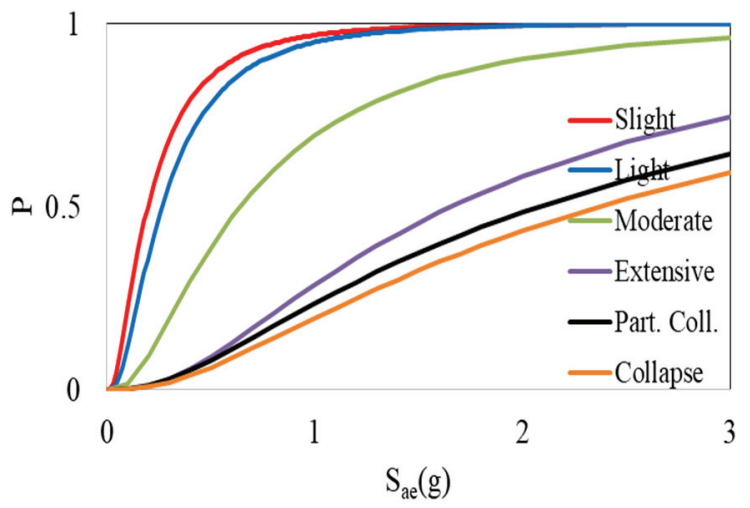

(b) Fragility Curves of the Retrofitted Building with Shear Walls (Global Damage Criteria)

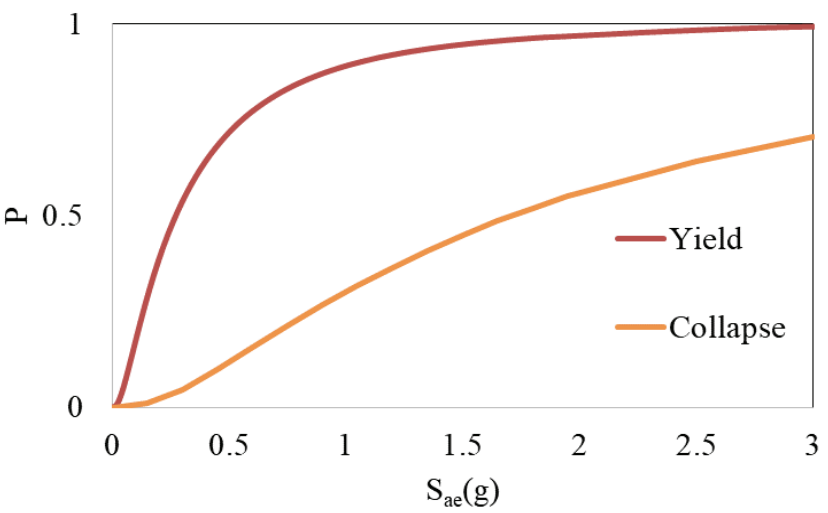

(c) Fragility Curves of Retrofitted Building with Shear Walls (Global Damage Criteria/IDA)

Figure 11 - Fragility Curves of the Retrofitted Building With Shear Walls 
The strain limit of the (partial) collapse section damage for columns. (collapse limit) has been reached before the strain limit of collapse section damage for beams (extensive damage limit) with a little increase in spectral acceleration for both existing and retrofitted (shear wall) structure. Thus, the probability of reaching life safety performance level could not be obtained for those buildings in case of using local damage criteria. Light, Moderate and Partial Collapse damage levels, given in Table 4, are related to IO, LS and CP performance levels, respectively. The performance levels are connected to damage levels based on the definitions of performance and damage levels.

Table 6 - Damage Probability for Target Performance (Local Damage Criteria)

\begin{tabular}{|c|c|c|c|}
\hline $\begin{array}{l}\text { Probability of } \\
\text { exceedance in } 50 \text { years }\end{array}$ & $\begin{array}{l}\text { Immediate } \\
\text { Occupancy }\end{array}$ & Life Safety & $\begin{array}{l}\text { Collapse } \\
\text { Prevention }\end{array}$ \\
\hline \multicolumn{4}{|c|}{ Existing } \\
\hline$\% 50$ & 98 & & \\
\hline$\% 10$ & & - & \\
\hline$\% 2$ & & & 74 \\
\hline \multicolumn{4}{|c|}{ Jacketing } \\
\hline$\% 50$ & 58 & & \\
\hline$\% 10$ & & 55 & \\
\hline$\% 2$ & & & 39 \\
\hline \multicolumn{4}{|c|}{ Shear wall } \\
\hline$\% 50$ & 76 & & \\
\hline$\% 10$ & & - & \\
\hline$\% 2$ & & & 34 \\
\hline
\end{tabular}

Table 7 - Damage Probability for Target Performance (Global Damage Criteria)

\begin{tabular}{|c|c|c|c|}
\hline $\begin{array}{c}\text { Probability of } \\
\text { exceedance in } 50 \text { years }\end{array}$ & $\begin{array}{l}\text { Immediate } \\
\text { Occupancy }\end{array}$ & Life Safety & $\begin{array}{l}\text { Collapse } \\
\text { Prevention }\end{array}$ \\
\hline & & Existing & \\
\hline$\% 50$ & 96 & & \\
\hline$\% 10$ & & 85 & \\
\hline \multirow[t]{2}{*}{$\% 2$} & & & 68 \\
\hline & & Jacketing & \\
\hline$\% 50$ & 58 & & \\
\hline$\% 10$ & & 38 & \\
\hline \multirow[t]{2}{*}{$\% 2$} & & & 12 \\
\hline & & Shear wall & \\
\hline$\% 50$ & 78 & & \\
\hline$\% 10$ & & 69 & \\
\hline$\% 2$ & & & 37 \\
\hline
\end{tabular}


Murat S. KIRÇIL, Erdem Çağlar KOCABEY

Table 8 - Damage Probability for Target Performance (Global Damage Criteria / IDA)

\begin{tabular}{|c|c|c|c|}
\hline $\begin{array}{l}\text { Probability of } \\
\text { exceedance in } 50 \text { years }\end{array}$ & Yielding & & Collapse \\
\hline & & Existing & \\
\hline$\% 50$ & 69 & & \\
\hline$\% 10$ & & - & \\
\hline \multirow[t]{2}{*}{$\% 2$} & & & 57 \\
\hline & & Jacketing & \\
\hline$\% 50$ & 57 & & \\
\hline$\% 10$ & & - & \\
\hline \multirow[t]{2}{*}{$\% 2$} & & & 6 \\
\hline & & Shear wall & \\
\hline$\% 50$ & 70 & & \\
\hline$\% 10$ & & - & \\
\hline$\% 2$ & & & 45 \\
\hline
\end{tabular}

As it is seen from the Tables 6-8, both retrofitting methods decrease the damage probability significantly. There is almost no difference between the probability of reaching IO Performance Level, obtained with local and global damage criteria (Table 6 and 7).

In case of using the local damage criteria (Table 6), the highest decrease in probability of exceeding the IO performance level is provided by the jacketing, while the highest decrease in probability of CP performance level is provided by shear walls. However; the difference in the probability of exceeding CP performance level of both retrofitting methods is not significant.

Jacketing is the most efficient method to decrease the damage probability in case of using global damage indicators since it provides significant decrease in damage probability at each considered performance level (Table 7) as compared with strengthening with shear walls. The authors believe that the main reason of this significant decrease is strong column-weak beam behavior which is provided by the increase in the strength and deformation capacity of the jacketed columns. This enhancement in strength can be observed from the IDA curves given in Fig.5. Note that improvement in the behavior of the building with jacketing depends on the shear reinforcement of jackets so that the premature shear failure can be prevented. In this study, it is assumed that sufficient amount of transverse reinforcement will be provided in jacketed columns.

\section{CONCLUSIONS}

Finally, the following conclusions can be drawn from the results of this study in addition to the discussion above:

- It is observed that analytic collapse probability (IDA) of the existing and the retrofitted 
buildings by jacketing $(\% 57, \% 6)$ are lower than the probability of CP performance level obtained based on either local $(\% 74, \% 39)$ or global $(\% 68, \% 12)$ damage limits and there is a reasonable margin between probability of reaching analytic collapse state obtained with IDA and that of collapse prevention performance level determined with both global and local criteria.

- However, as it is seen from Tables 6-8, the probability of reaching collapse state determined through IDA for the retrofitted building with shear walls (Table 8) is higher than the probability of reaching CP performance level determined with local and global damage criteria given in Table 6 and 7. This result shows that both local and global criteria for CP performance level, given in codes or proposed by other researchers, are not always consistent with the analytic collapse limit. However, this observation must be verified by examining more sample structures with different amount of shear wall area so that it can be determined whether shear dominated behavior of the structure is effective on this observation or not. Strengthening with shear walls is almost inevitable with increasing building height so that lateral displacements can be limited. In such a case, analytic collapse limit should be determined and used as the upper limit or inter-story drift ratio of collapse instead of the collapse limit given by codes or other similar documents.

- The Immediate Occupancy Performance Level is defined by Turkish Seismic Design Code [19] as "none or negligible damage" in structural system. Furthermore, yielding capacity determined via IDA represents the onset of yielding. Thus, it is expected to have similar probability of reaching the yielding and the IO performance level. The probability of reaching the Immediate Occupancy Performance Level determined with local and global criteria and the probability of yield determined with IDA are similar $(\% 58, \% 58$, $\% 57$ ) only for the retrofitted building with jacketing. However, yielding probability of the existing building $(\% 69)$ is significantly lower than the probability of reaching the IO Performance Level $(98 \%, 96 \%)$. Yielding probability $(70 \%)$ of the retrofitted building with shear walls is still lower than the probability of reaching IO Performance Level given in Table 6 and 7 (76\% and 78\%). However; the difference is not as significant as observed for the existing building.

Those differences in damage probability indicate the importance of the damage criteria and corresponding limits used for the determination of damage probability. Damage state or performance level limits -either local or global- must be selected carefully and upper and lower limits (onset of yield and collapse), at least, must be determined analytically so that realistic estimations can be made.

Note that local damages such as shear or axial failure of structural system elements are not considered within the scope of this study; so that, the retrofitting methods can be compared clearly. On the other hand, those failure types can be observed during the evaluation and design process and they may require application of some local strengthening techniques to prevent brittle failure of those elements. However, it is believed that the existence of this type of deficiencies (when they don't change the global structural behavior significantly) does not cause significant changes in the observations which are made within the scope of this study.

A building with a regular plan has been investigated so that the individual effect of considered retrofitting methods can be compared clearly; however, the plan layout of the main portion of the existing building stock is not as regular as such. Therefore, for a building with a highly 
irregular plan, the probable strengthening method will be the combination of the considered methods within the scope of this study.

\section{References}

[1] Ay, B. Ö., Erberik, M. A., Vulnerability of Turkish Low-Rise and Mid-Rise Reinforced Concrete Frame Structures. J. Earthq. Eng., 12(S2), 2-11, 2008.

[2] Kirçil, M. S., Polat, Z., Fragility analysis of mid-rise R/C frame buildings. Eng. Struct., 28(2006), 1335-1345, 2006.

[3] Borekci, M., Kirçil M.S., Fragility analysis of R/C frame buildings based on different types of hysteretic model. Struct. Eng. Mech., 39(6), 795-812, 2011.

[4] Martins , L., Silva, V., Marques, M., Crowley, H., Delgado, R., Development and assessment of damage-to-loss models for moment-frame reinforced concrete buildings. Earthq. Eng.\& Struc. Dyn., 45(5), 797-817, 2016.

[5] Akkar, S.,Sucuoglu, A. Displacement-Based Fragility Functions for Low- and Mid-rise Ordinary Concrete Buildings. Earthq. Spect., 21(4), 901-927, 2005.

[6] Langa, K., Bachmann, H. (2004), On the Seismic Vulnerability of Existing Buildings: A Case Study of the City of Basel. Earthq. Spect., 20(1), 43-66, 2004.

[7] Kazantzi, A.K., Righiniotis, T.D., Chryssanthopoulos, M.K., A Simplified Fragility Methodology for Regular Steel MRFs. J. of Struct. Eng., 15, 390-403, 2011.

[8] Ji, J., Kuchma, A.D.,Elnashai, A.S., Seismic Fragility Relationship of Reinforced Concrete High-Rise Buildings. The Struc. Des. Tall and Special Buildings, 18, 259$277,2009$.

[9] Ellingwood, B.R., Celik, O.C., Kinali, K., Fragility assessment of building structural systems in Mid-America. Earthq. Eng.\& Struc. Dyn., 36, 1935-1952, 2007.

[10] Pasticier, L., Amadio, C., Fragiacomo, M., Non-linear seismic analysis and vulnerability evaluation of a masonry building by means of the SAP2000 V.10 code. Earthq. Eng.\& Struc. Dyn., 37, 467-485, 2008.

[11] Inel, M., Ozmen, H.B., Seismic performance evaluation of school buildings in Turkey. Struct. Eng. Mech., 30(5), 535-558, 2008.

[12] Senel, S.M., Kayhan, A.H., Fragility based damage assesment in existing precast industrial buildings: A case study for Turkey. Struct. Eng. Mech., 34(1), 39-60, 2010.

[13] Silva, V., Crowley, H., V., Humberto, Pinho, R., Sousa, L., Investigation of the characteristics of Portuguese regular moment-frame RC buildings and development of a vulnerability model. Bull. of Earthq. Eng., 13(5), 1455-1490, 2015.

[14] Jeong, S.H., Mwafy, A.M., Elnashai, A.S., Probabilistic seismic performance assessment of code-compliant multi-story RC buildings. Eng. Struct., 34 (2012), 527$537,2012$. 
[15] Casotto, C., Silva, V., Crowley, H., Nascimbene, R., Pinho, R., Seismic fragility of Italian RC precast industrial structures. Eng. Struct., 94 (2015), 122-136, 2015.

[16] Hueste, M.B.D., Bai, J.W., Seismic retrofit of a reinforced concrete flat-slab structure: Part II-seismic fragility analysis. Eng. Struct., 29 (2007), 1178-1188, 2007.

[17] Turkish Seismic Design Code, Specifications for buildings to be built in seismic zones, Ankara, Turkey, Ministry of Public Works and Settlement, 2007.

[18] Requirements for Design and Construction of Reinforced Concrete Structures TS 500, Ankara, Turkey, Turkish Standard Institution, 2000.

[19] Rosetto, T. and Elnashai, A.E., Derivation of vulnerability functions for European-type RC structures based on observational data. Eng. Struct., 25(10), 1241-1263, 2003.

[20] Vamvatsikos, D., Cornell, C.A., Incremental Dynamic Analysis. Earthq. Eng.\& Struc. Dyn., 31(3), 491-514, 2001.

[21] Seismostruct, Software for Finite Element Analysis of Structures, Seismosoft Inc., Pavia, Italy, 2014. www.seismosoft.com/seismostruct

[22] Jeong, S.H., Elnashai, A.S., Probabilistic fragility analysis parameterized by fundamental response quantities. Eng. Struct., 29 (2007), 1238-1251, 2007.

[23] Bartlett, F.M., MacGregor, J.G., Statistical Analysis of the Compressive Strength of Concrete in Structures. ACI Materials J, 93(2), 158-168, 1996. 